\title{
Prevalence of clinical and electrocardiographic evidence of ischaemic heart disease in the older population
}

\author{
A. H. Kitchin, C. P. Lowther, and J. S. Milne \\ From Western General and Royal Victoria Hospitals, Edinburgh
}

In 487 subjects aged 62 to 90 years who formed a random sample of the 27,000 older people living in a defined area of Edinburgh, the prevalence of positive responses to Rose's questionnaire on angina and infarction and of coded electrocardiographic abnormalities was recorded as part of a clinical survey, including blood pressure, height, weight, skinfold thickness, heart size, and presence of cardiac murmurs. The results were compared with similar data available in younger age groups.

$A$ history of angina was given by to per cent of the sample. Electrocardiographic abnormalities strongly suggestive of ischaemic heart disease were present in 6 per cent and others possibly due to ischaemic heart disease in a further 24 per cent. Forty-four per cent of subjects had no codable electrocardiographic abnormality. Electrocardiographic evidence of ischaemic heart disease increased with age. Smoking habits, obesity, and hypertension were unrelated to manifestations of ischaemic heart disease in this group. The pattern of left axis deviation was present in 8.8 per cent and exceeded $-45^{\circ}$ in 4.4 per cent of the sample.

Age-specific incidence and mortality rates for coronary heart disease increase with age in both sexes, approximately doubling for every to years of advancing age (Rose, 1972). Since the natural history of the disease is still largely unknown its prevalence in the elderly as the result of the operation of risk factors, known and unknown, and selective mortality is of interest. It is believed, for example, that 'stable' angina is associated with a relatively long survival (Rose, I97I), while on the other hand sudden death from myocardial infarction or ischaemic arrhythmia may be the first clinical manifestation of the disease (Lovell and Prineas, 197I).

Various risk factors have been more or less certainly identified. These include high blood pressure, raised level of serum cholesterol or triglyceride, a diet rich in saturated fats, a sedentary mode of life, smoking, and carbohydrate intolerance. Most studies relate to patients in middle-age though the maximal incidence of the disease is in the older age groups. Is clinical ischaemic heart disease more prevalent in the old than in the middle-aged, and does it show the same relation to risk factors as has been identified in the latter?

Received 9 May 1973.
Numerous studies report the prevalence of manifestations of the disease in various groups. The great majority of these, however, are not representative of the general population but relate to particular industrial or occupational groups (Stamler et al., 1960; Acheson, 196I; Paul et al., 1963) or to patients presenting to general practitioners or in hospital (Painter et al., 1960; Eisenberg et al., 196I). A few large-scale longitudinal studies such as the Framingham one (Dawber et al., 1962) are in progress and report the incidence in family groups followed as age-cohorts. Even here, however, the representative nature of the subjects studied is open to question and the fact that they are under long-term study may influence the outcome. They refer also to a different climatic, genetic, and cultural background from our own. To gain a reliable estimate of the prevalence of ischaemic heart disease, the selection of an unbiased sample of the population in question is crucial but is seldom possible. The setting up of a study of older people living in a defined area of Edinburgh offered such an opportunity.

It is proposed to study over a five-year period a randomly selected sample of the older population over the age of 60 . The objectives are:- 
a) to ascertain the prevalence of the various manifestations of ischaemic heart disease at the start of the five-year period;

b) to measure and record a number of other features including age, sex, weight, height, obesity, heart size, blood pressure, glycosuria, and smoking history, and

c) to record the incidence of the development of new cardiac manifestations over the five-year period.

The questions which it is hoped to answer are -

I) How widespread is ischaemic heart disease in the older population?

2) What are the commoner manifestations, and are they the same as those recorded in younger patients ? 3) Are the risk factors which have been identified in younger groups of hospital patients confirmed in the older population?

4) What is the prognosis of ischaemic heart disease in its various manifestations in this age group?

The present paper reports the first part of this study concerned with the prevalence of manifestations of the disease and their relation to other factors.

\section{Subjects and methods}

The subjects were 215 men and 272 women aged 62 to 90 years who formed a random sample of the 27,000 older people living in a defined area of the city. The method of sampling, including a comparison of respondents and non-respondents, has been reported elsewhere (Milne, Maule, and Williamson, 197 Ib). The study took place during a 24-month period.

Standardized validated techniques were used and measurements of reproducibility were obtained.

I) Rose's questionnaire in respect of angina pectoris and possible myocardial infarction (Rose, 1962; Rose and Blackburn, 1968) was administered to all subjects by one medically qualified observer (J.S.M.). Before beginning the study the observer made use of training material supplied by Professor Rose.

2) A r2-lead electrocardiogram was recorded for each subject using a direct writing portable electrocardiograph. The records were read and coded according to the Minnesota classification (Blackburn et al., 1960) by two physicians experienced in electrocardiography (C.P.L. and A.H.K.). They coded the records independently and where the results disagreed $(40 \%)$ the record was re-examined and an agreed coding supplied.

3) A posteroanterior chest radiograph was carried out using a 6-foot tube-film distance. The Harpenden anthropometer with straight branches was used to measure the maximum transverse cardiac diameter and lateral chest diameter (maximum diameter between inner rib margins). The ratio of these measurements gave the cardiothoracic ratio (CTR).

4) Other measurements recorded were height, weight to nearest $100 \mathrm{~g}$ on a lever balance, the skinfold thickness measured as the sum of the $\log$ transformations of triceps, biceps, subscapular and suprailiac skinfolds on the right side using a Harpenden caliper (Edwards et al., 1955), and arterial blood pressure measured with the London School of Hygiene instrument.

5) A questionnaire covering cardiovascular disease and cigarette smoking (Medical Research Council, 1965) was administered to all subjects.

6) A general medical examination of the subjects was carried out and recorded on proformata.

Reproducibility of both questionnaires was previously tested (Milne et al., I97ra). Reproducibility of the measurements of blood pressures, CTR, and skinfold thickness, made by using the same group of persons on two occasions, was tested. The SD of the mean difference in no case exceeded 4.2 per cent of the mean of the dimension concerned. The complete data were coded, stored on magnetic tape, and analysed using standard computer techniques.

\section{Results}

\section{I) Angina and probable infarction}

The replies to Rose's questionnaire are shown for two age groups of men and women in Table $\mathrm{I}$. The difference in prevalence of angina between men (10.3\%) and women (11.6\%) is not significant but a significantly greater proportion of men (10.8\%) compared with women $(3.4 \%)$ gave a history of possible myocardial infarction $\left(\chi^{2}=10.50, \mathrm{P}<0.01\right)$. The severer grade of angina, i.e. that occurring on walking at an ordinary pace on level ground, was present in 6 per cent of men and 4.5 per cent of women. No significant age difference in prevalence was found in either sex for either diagnosis.

TABLE I Percentage frequency of manifestations of ischaemic heart disease by age and sex

\begin{tabular}{|c|c|c|c|c|c|}
\hline \multirow{2}{*}{$\begin{array}{l}\text { Age and } \\
\text { Sex }\end{array}$} & \multirow[t]{2}{*}{ No. } & \multicolumn{2}{|c|}{ Rose's questionnaire } & \multicolumn{2}{|c|}{ Electrocardiogram } \\
\hline & & Angina & Infarction & Probable & Possible \\
\hline \multicolumn{6}{|l|}{ Men } \\
\hline $62-69$ & 122 & $9 \cdot 1$ & 10.8 & $5 \cdot 0$ & 16.5 \\
\hline $\begin{array}{l}70+ \\
\text { All }\end{array}$ & 93 & $12 \cdot 0$ & 10.9 & $8 \cdot 4$ & $26 \cdot 0$ \\
\hline & & 10.3 & & $7 \cdot 1$ & 20.5 \\
\hline \multicolumn{6}{|l|}{ Women } \\
\hline $62-69$ & I 37 & I I 0 & $1 \cdot 5$ & $4 \cdot 4$ & 19.0 \\
\hline $\begin{array}{l}70+ \\
\text { All }\end{array}$ & $\begin{array}{l}135 \\
272\end{array}$ & $\begin{array}{l}I 2 \cdot 2 \\
\text { II } 6\end{array}$ & $\begin{array}{l}5 \cdot 4 \\
3 \cdot 4\end{array}$ & $\begin{array}{l}5 \cdot 9 \\
5 \cdot 3\end{array}$ & $\begin{array}{l}32 \cdot 2 \\
26 \cdot 0\end{array}$ \\
\hline Total & 487 & II.O & $6 \cdot 7$ & $6 \cdot 1$ & 24.0 \\
\hline
\end{tabular}

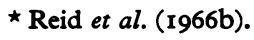




\section{2) Electrocardiographic abnormalities}

Electrocardiographic data were incomplete in 5 subjects. Two hundred and fourteen cardiographs were completely normal ( $44 \%$ ).

Following Reid et al. (1966b) the electrocardiographic changes which were recognized as indicative of ischaemic heart disease were as follows.

I) Probable ischaemic heart disease (Type I) Minnesota coding (I I.I-I 2.8 or VII I).

2) Possible ischaemic heart disease (Type 2) - Minnesota coding (I 3.I-I 3.6 or IV I-3 or V I-3).

Broadly speaking Type I represents major $\mathrm{Q}$ or $\mathrm{QS}$ patterns or left bundle-branch block, while Type 2 represents minor $Q$ abnormalities or ST-T changes. Type I was present in 6.I per cent of cardiographs and Type 2 in 24 per cent making a total of 30.1 per cent (Table I).

The prevalence of various abnormalities is shown in Table 2.

\section{3) Effect of age and sex}

The prevalence of electrocardiographic abnormalities increases with age (Table I). Many more men than women give a history of possible infarction.

\section{4) Cardiothoracic ratio}

The numbers of men and women in the sample with cardiothoracic ratio over 50 per cent are
TABLE 3 Cardiothoracic ratio and ischaemic heart disease

$\begin{array}{llll}\hline & & \multicolumn{2}{c}{\text { Per cent with }} \\ & & \multicolumn{2}{c}{\text { CTR }>50 \%} \\$\cline { 2 - 3 } & & \text {$\left.Men } & \text { Women } \\ \hline \text { History } & \text { Angina } & 15 \cdot 8 & 71 \cdot 4 \\ & \text { No angina } & 22 \cdot 7 & 56 \cdot 4 \\ & \text { Myocardial infarct } & 20 \cdot 0 & 75 \cdot 0 \\ & \text { No myocardial infarct } & 22 \cdot 2 & 57 \cdot 6 \\ \hline \text { Electrocardiogram } & \text { Type I changes } & 21 \cdot 1 & 69 \cdot 4 \\ & \text { Type 2 changes } & 22 \cdot 2 & 56 \cdot 6 \\ & \text { Types I +2 } & 31 \cdot 9 \\ & \text { Neither } & 13 \cdot 0\end{array}\right\} \begin{gathered}69 \cdot 7 \\ \end{gathered}$

* Significant differences $(P<0.01)$.

shown in Table 3 in respect of the presence or absence of angina, possible myocardial infarction, and electrocardiographic evidence of 'probable' ischaemic heart disease (Type I) and 'probable + possible' ischaemic heart disease (Types I and 2). In the last named category a significantly higher proportion of men $\left(\chi^{2}=9.91, P<0.01\right)$ and women $\left(\chi^{2}=\mathrm{II} \cdot 82, \mathrm{P}<0.01\right)$ classed as having ischaemic heart disease had a cardiothoracic ratio $>50$ per cent. This difference was not present in the other three categories of ischaemic heart disease.

The sex difference in CTR in this age group shown in Table 3 is associated with changes in the transthoracic rather than in the cardiac diameter (unpublished observation).

TABLE 2 Prevalence of coded electrocardiographic abnormalities in men and women

\begin{tabular}{|c|c|c|c|c|c|c|c|c|}
\hline Abnormality & Code & & $\begin{array}{l}\text { Male } \\
(214)\end{array}$ & $\%$ & $\begin{array}{l}\text { Female } \\
(268)\end{array}$ & $\%$ & $\begin{array}{l}\text { Total } \\
(482)\end{array}$ & $\%$ \\
\hline $\begin{array}{l}\text { No codable abnormality } \\
\text { Major Q/QS patterns } \\
\text { Minor Q/QS patterns } \\
\text { Left axis deviation } \\
\text { Right axis deviation } \\
\text { Left ventricular hypertrophy } \\
\text { Right ventricular hypertrophy } \\
\text { ST depression } \\
\text { T inversion or flattening } \\
\text { AV block } \\
\text { Bundle-branch block L } \\
\text { " " " R } \\
\text { Atrial fibrillation " R incomplete } \\
\text { Other arrhythmias }\end{array}$ & $\begin{array}{l} \\
\text { I } \\
\text { II } \\
\text { II } \\
\text { III } \\
\text { III } \\
\text { IV } \\
\text { V } \\
\text { VI } \\
\text { VII } \\
\text { VII } \\
\text { VII } \\
\text { VIII } \\
\text { VIII }\end{array}$ & $\begin{array}{l}I-2 \\
3 \\
1 \\
2-3 \\
I \\
2 \\
I-3 \\
I-3 \\
I-3 \\
1 \\
2 \\
3 \\
3\end{array}$ & $\begin{array}{r}104 \\
12 \\
5 \\
22 \\
4 \\
8 \\
7 \\
28 \\
50 \\
8 \\
3 \\
5 \\
3 \\
5 \\
13\end{array}$ & $\begin{array}{l}49 \\
5 \cdot 6 \\
2 \cdot 3 \\
10 \cdot 2 \\
1 \cdot 9 \\
3 \cdot 7 \\
3 \cdot 3 \\
13 \\
23 \\
3 \cdot 7 \\
1 \cdot 4 \\
2 \cdot 3 \\
1 \cdot 4 \\
2 \cdot 3 \\
6 \cdot 1\end{array}$ & $\begin{array}{r}110 \\
14 \\
6 \\
19 \\
0 \\
39 \\
5 \\
64 \\
80 \\
8 \\
0 \\
6 \\
4 \\
7 \\
11\end{array}$ & $\begin{array}{l}41 \\
5 \cdot 2 \\
2 \cdot 2 \\
7 \cdot 1 \\
0 \\
14 \cdot 5 \\
1 \cdot 9 \\
24 \\
30 \\
3 \cdot 0 \\
0 \\
2 \cdot 2 \\
1 \cdot 5 \\
2 \cdot 6 \\
4 \cdot 1\end{array}$ & $\begin{array}{r}214 \\
26 \\
11 \\
41 \\
4 \\
47 \\
12 \\
92 \\
130 \\
16 \\
3 \\
11 \\
7 \\
12 \\
24\end{array}$ & $\begin{array}{c}44 \\
5.4 \\
2.3 \\
8.5 \\
0.8 \\
9.7 \\
2.5 \\
19.1 \\
27 \\
3.3 \\
0.6 \\
2.3 \\
1.5 \\
2.5 \\
5.0\end{array}$ \\
\hline $\begin{array}{l}\text { 'Probable ischaemic heart disease'‡ } \\
\text { 'Possible ischaemic heart disease' }\end{array}$ & $\begin{array}{c}\text { I I-2 or } \\
\text { I } 3 \text { or IV } \\
\text { V I-3 }\end{array}$ & $\begin{array}{l}\text { VII I } \\
\text { I-3 or }\end{array}$ & $\begin{array}{l}15 \\
44\end{array}$ & $\begin{array}{l}7 \cdot I \\
2 I \cdot 0\end{array}$ & $\begin{array}{l}14 \\
71\end{array}$ & $\begin{array}{r}5 \cdot 3 \\
26 \cdot 0\end{array}$ & $\begin{array}{r}29 \\
115\end{array}$ & $\begin{array}{r}6 \cdot 1 \\
24 \cdot 0\end{array}$ \\
\hline
\end{tabular}

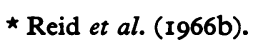




\section{5) Association of history and electrocardio- graphic abnormalities}

There was a higher prevalence of electrocardiographic changes in those with a history of angina or infarction $(46 \%)$ than in those without $(28 \%)$. However, a large number of subjects with a history suggestive of ischaemic heart disease had a normal electrocardiogram $(39 / 72=54 \%)$ and a large number of subjects with an abnormal, presumed ischaemic, electrocardiogram gave no corresponding history (II $5 / 405=28 \%$ ).

In the presence of pathological $Q$ waves (Type $I$ ) there is little doubt of the existence of ischaemic heart disease. Type 2, however, consists of ST-T changes which might be associated with other conditions, notably hypertension and valvular heart disease, especially aortic. The II5 subjects with Type 2 electrocardiograms were therefore analysed further. Of these II 5 subjects only 66 had no explanation other than coronary artery disease for their electrocardiographic abnormality, and of these 55 were asymptomatic. The other cases were, in the majority, patients with left ventricular hypertrophy caused by hypertension or valvular disease.

\section{6) Total prevalence of ischaemic heart disease}

If we take as evidence of ischaemic heart disease, (I) a positive history of angina or possible infarction, (2) probable electrocardiographic evidence (Type I), or (3) possible electrocardiographic evidence (Type 2) not explicable on a basis of hypertension or valvular disease, the prevalence is made up as shown in the Fig. This shows diagrammatically the relation between the three manifestations of ischaemic heart disease considered in this study.

\section{7) Risk factors}

Table 4 shows the relative frequency of three known risk factors for ischaemic heart disease between the groups of subjects who had or who had not presumptive evidence of ischaemic heart disease, either historically or electrocardiographically. There was no difference between the two groups as regards smok-

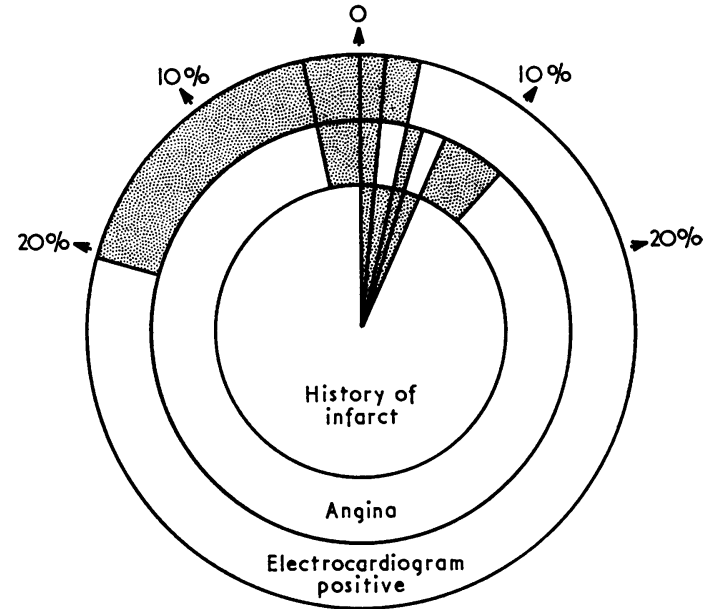

FIG. Relative frequency and correspondence of manifestations of ischaemic heart disease

ing or obesity. Systolic and diastolic hypertension were defined as pressures of 160 or over and 100 or over respectively. There was a higher prevalence of systolic and diastolic hypertension in women ( $57 \%$ and $19 \%$ ) than in men (38\% and $11 \%$ ). Increasing age raised the prevalence of systolic hypertension in women ( 46 to $68 \%$ ) but not in men ( 41 to $33 \%$ ). In patients with probable ischaemic heart disease (i.e. those with a history of angina or infarction or pathological $Q$ waves on the electrocardiogram) there was a lower prevalence of diastolic and diastolic+systolic hypertension than in the nonischaemic group, but no difference as regards systolic hypertension alone.

\section{8) Increased left ventricular voltage pattern}

Twelve men and 46 women had the voltage criteria of left ventricular hypertrophy. The majority had hypertension, either systolic ( 9 men, 32 women), diastolic (4 men, I6 women), or both ( 4 men, I6 women). Two men and four women had the hypertrophy pattern with normal blood pressures and evidence of myocardial infarction on electrocardio-

TABLE 4 Comparison of subjects with and without evidence of ischaemic heart disease

\begin{tabular}{|c|c|c|c|c|c|c|c|c|c|c|c|}
\hline \multirow[t]{3}{*}{ Percentage frequency of } & \multirow[b]{3}{*}{ No. } & \multirow{2}{*}{\multicolumn{2}{|c|}{ Smoking }} & \multicolumn{4}{|c|}{ Hypertension } & \multicolumn{4}{|c|}{ Obesity } \\
\hline & & & & \multicolumn{2}{|c|}{ Systolic } & \multicolumn{2}{|c|}{ Diastolic } & \multicolumn{2}{|c|}{$\overline{\text { Skinfold } \star}$} & \multicolumn{2}{|c|}{$W / H^{2} \dagger$} \\
\hline & & $\bar{M}$ & $F$ & $\bar{M}$ & $F$ & $\bar{M}$ & $F$ & $M$ & $F$ & $M$ & $F$ \\
\hline $\begin{array}{l}\text { Subjects with evidence of ischaemic disease } \\
\text { Subjects without evidence of ischaemic heart disease }\end{array}$ & $\begin{array}{l}144 \\
343\end{array}$ & $\begin{array}{l}85 \\
93\end{array}$ & $\begin{array}{l}21 \\
29\end{array}$ & $\begin{array}{l}38 \\
38\end{array}$ & $\begin{array}{l}61 \\
55\end{array}$ & $\begin{array}{c}7 \cdot 8 \\
12\end{array}$ & $\begin{array}{l}18 \\
23\end{array}$ & $\begin{array}{l}21 \\
28\end{array}$ & $\begin{array}{l}65 \\
66\end{array}$ & $\begin{array}{l}24 \\
27\end{array}$ & $\begin{array}{l}30 \\
34\end{array}$ \\
\hline
\end{tabular}

* Sum of $\log$ transformations of 4 skinfold thicknesses.

+ Weight $/$ height $^{2}$. 
gram or in the history. A systolic murmur was present in two men (I hypertensive and I normotensive) and in 17 women ( 12 hypertensive and 5 normotensive). One man and six women had the hypertrophy pattern with normal blood pressure, no murmurs, and no evidence of infarction. Systolic hypertension was present in 70/203 men and $124 / 227$ women without left ventricular hypertrophy pattern, while diastolic hypertension was present in 21 men and 42 women.

\section{9) Left axis deviation}

The significance of a mean $Q R S$ vector of $-30^{\circ}$ or more is that it may be associated with conduction block in the anterior portion of the left bundlebranch (left anterior hemiblock; Grant, 1956; Rosenbaum, 1970). It may occur acutely in myocardial infarction or chronically in ischaemic heart disease; if associated with right bundle-branch block there is a danger of trifascicular block and idioventricular rhythm. The prevalence of left axis deviation in the general population is unknown. It was present in 44 of the present 477 cardiograms $(8.8 \%)$. In 22 of these the $\hat{A}_{\mathrm{QRs}}$ exceeded $-45^{\circ}$ and in 8 it exceeded $-60^{\circ}$. There were 22 men and 22 women. In 27 of them the cardiogram was otherwise normal, and in 24 there was no history of ischaemic heart disease. In a further 15 cases it was associated with ST-T changes, and 6 of these had an ischaemic history. It was not associated with an increased prevalence of hypertension. In 3 cases there was also incomplete right bundle-branch block.

\section{0) Summary}

A history of angina was given by 10.3 per cent of men and II.6 per cent of women in the sample. Severe angina was present in 6 per cent and 4.5 per cent, respectively. More men than women gave a history of possible myocardial infarction, 10.8 per cent as opposed to 3.4 per cent. 6.1 per cent of the cardiograms showed Type I changes while 24 per cent showed Type 2 changes, i.e. possible ischaemic disease.

There was no sex difference in the prevalence of electrocardiographic abnormalities which, however, increased with age while a history of angina or infarction did not. Cardiac enlargement was more frequent in the presence of electrocardiographic changes but no more frequent in those giving a history of angina or infarct. Fifty-four per cent of subjects with a history of angina or infarction had no ischaemic changes in the electrocardiogram, while 28 per cent of subjects with such changes gave no history of angina or infarction. If a history of angina or infarction and/or the presence of Type $I$ electrocardiographic changes is taken as evidence of probable ischaemic heart disease, the total probable prevalence in the sample was 18 per cent. If we include in addition Type 2 or possible electrocardiographic changes the figure rises to 28 per cent.

Smoking history, obesity, and hypertension were unrelated to the presence of manifestations of ischaemic heart disease in this group. Hypertension was commoner in women and was associated with voltage changes of left ventricular hypertrophy on the electrocardiogram. Other electrocardiographic abnormalities were rare with the exception of the pattern of left axis deviation present in 8.8 per cent of the sample and marked in 4.4 per cent which is recognized as commonly due to damage or degeneration of the anterior division of the left bundlebranch.

\section{Discussion}

We report the response to a standardized angina and infarction questionnaire and the occurrence of specific coded electrocardiographic abnormalities in a randomly selected sample of the older population in a defined area. For comparison two studies in the same age group, using careful sampling methods, are of particular relevance. One is the postal questionnaire carried out by Reid et al. (I966a) on a random sample of subjects aged 65 to 74 (Table 5). The main differences are the lower prevalence among women of angina shown by Reid et al. and the lesser sex difference shown by them in respect of possible infarction. Our figures confirm the Framingham findings (Dawber et al., 1962) that in men angina and history of infarct are equally common while in women the latter is much less common.

Kennedy and Caird (1972) in an electrocardiographic survey of 400 subjects over 65 forming stratified random samples from two towns in Scotland found a similar prevalence of abnormal electrocardiograms, to that found in the present study (Table 6). They showed a higher prevalence of pathological $Q$ waves and of bundle-branch block both right and left, while non-specific ST and T changes were less common than in the present data.

TABLE 5 Percentage frequency of history of ischaemic heart disease

\begin{tabular}{llrc}
\hline History of & Source & Men & Women \\
\hline Angina & \{ Reid et al. (1966a) & 10.4 & 5.8 \\
Present data & 10.3 & 11.6 \\
Possible & Reid et al. (1966a) & 7.9 & 4.0 \\
infarction & Present data & 10.8 & 3.4 \\
\hline
\end{tabular}


TABLE 6 Percentage frequency of coded electrocardiographic abnormalities

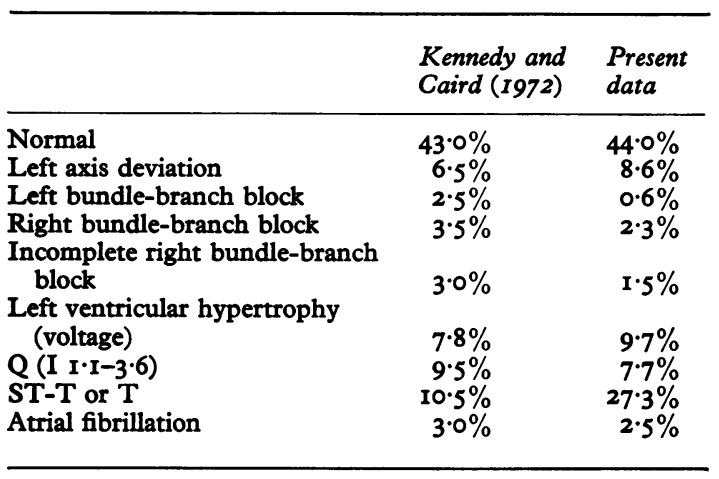

As regards younger age groups the survey of male postal workers aged 40 to 59 carried out by Reid et al. (1966b) affords some comparison with the 215 older male subjects in the present series (Table 7). In the older group of men a majority have a codable abnormality in the electrocardiogram and there are steep rises in the prevalence of major $\mathrm{Q} / \mathrm{QS}$ patterns, ST-T patterns, and history of myocardial infarction. Comparable studies of the prevalence of ischaemic heart disease in Europe are reported by Rose (1967). Again the present figures show a much higher prevalence of angina (10\% as opposed to $0.3-6.3 \%$ ), possible infarction (10.8\% to $1 \cdot 5-9.6 \%$ ), probable

TABLE 7 Effect of age on percentage prevalence of electrocardiographic abnormalities in men

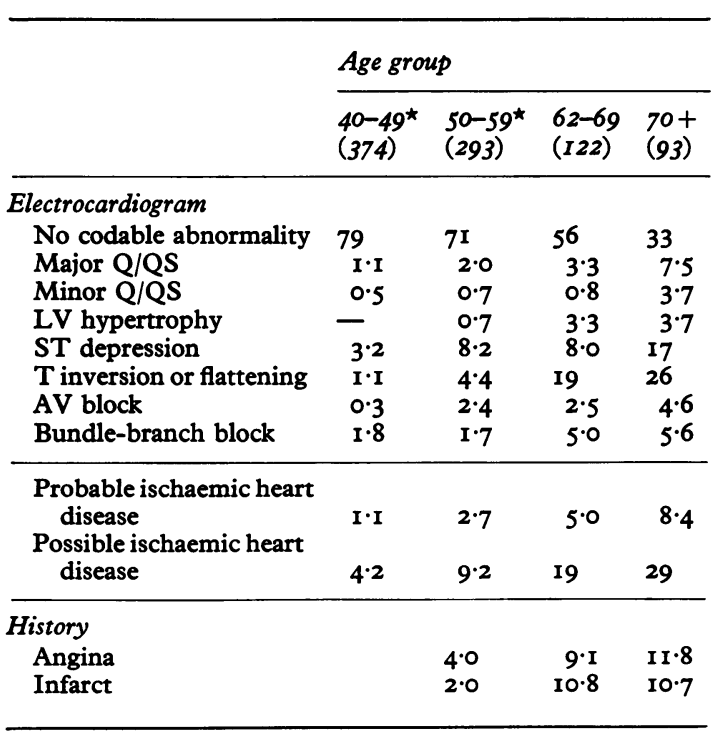

* Data from Reid et al. (1966b). ischaemia on electrocardiogram (6. $\mathrm{I} \%$ to $\mathrm{I} \cdot 4-2 \cdot 6 \%)$, and possible ischaemia (25\% to $5 \cdot 5-12 \cdot 2 \%)$.

How probable is it that the present results validly represent the prevalence of ischaemic heart disease ? The first problem is what is meant by ischaemic heart disease. Coronary atheroma which is the underlying pathology of the great bulk of the disease is present at an early age in many clinically healthy people. Its progression to the point of causing symptoms cannot be documented short of serial coronary angiography. The cardinal symptom is angina, yet severe occlusive disease may be present with this symptom which correlates poorly with the extent of the disease. Angina itself is not a risk to survival. Death occurs as a result of myocardial infarction or local critical ischaemia causing arrhythmia, both of which are unpredictable complications of the disease, and which may be its first and only manifestation (Lovell and Prineas, I97I). Silent myocardial infarction may occur without symptoms (Lindberg et al., 1960). Atypical presentations of myocardial infarction occur commonly in elderly people (Pathy, 1967). The resting electrocardiogram is frequently normal in patients at risk of death from

TABLE 8 Final diagnosis of patients admitted to coronary care unit, Western General Hospital, Edinburgh, 1966-68

\begin{tabular}{|c|c|c|c|c|}
\hline \multicolumn{3}{|l|}{ Condition } & No. & $\%$ \\
\hline \multicolumn{3}{|c|}{ Myocardial infarction } & 508 & 59 \\
\hline Other cardiac: & $\begin{array}{l}\text { ischaemia } \\
\text { arrhythmias } \\
\text { pericarditis } \\
\text { LV failure } \\
\text { dissecting aneurysm } \\
\text { other }\end{array}$ & $\begin{array}{r}143 \\
52 \\
20 \\
17 \\
3 \\
12\end{array}$ & 247 & 28 \\
\hline Respiratory: & $\begin{array}{l}\text { pulmonary infarct } \\
\text { pneumonia } \\
\text { bronchitis } \\
\text { pneumothorax } \\
\text { other }\end{array}$ & $\begin{array}{r}\text { I5 } \\
\text { II } \\
\text { 10 } \\
3 \\
6\end{array}$ & 45 & 5 \\
\hline Gastrointestinal: & $\begin{array}{l}\text { peptic ulcer } \\
\text { oesophagitis } \\
\text { hiatus hernia } \\
\text { other }\end{array}$ & $\begin{array}{r}10 \\
6 \\
5 \\
12\end{array}$ & 33 & 4 \\
\hline Skeletal pain & & & 10 & I \\
\hline Miscellaneous: & $\begin{array}{l}\text { syncope } \\
\text { cerebrovascular acciden } \\
\text { hyperventilation } \\
\text { other }\end{array}$ & $\begin{array}{r}12 \\
\text { nt } 4 \\
2 \\
\text { I I }\end{array}$ & 29 & 3 \\
\hline Total & & & 872 & 100 \\
\hline
\end{tabular}


ischaemic heart disease. Clearly the identifiable manifestations will yield many false negatives.

False positive responses in terms of ascribing chest pain from other causes to ischaemic heart disease are notoriously common (Rose, 1968; Zeiner-Henriksen, 1972). Pain simulating myocardial infarction but due to other causes and resulting in admission to a coronary care unit is common (Table 8; also Säwe, I97I), and a retrospective history of such pain must include a large number of false positives in patients who are not fully investigated in hospital. Friesinger and Smith (1972) found positive arteriographic evidence of coronary artery disease in 92 per cent of patients with typical angina and 40 per cent of those with atypical pain. In those with pathological $Q$ waves in the electrocardiogram all were positive if there was anginal pain. Similarly with ST-T changes; if accompanied by angina they were always associated with angiographic changes but were so in only a minority of those without pain.

Even the electrocardiographic changes of ischaemic heart disease are not specific. Broad pathological $Q$ waves are the most convincing evidence of previous infarction but Horan, Flowers, and Johnson (197I) report that an isolated broad $Q$ in inferior or anterior leads has only a 50 per cent chance of being associated with an infarct. Horizontal ST depression in the left praecordial leads is likewise highly suggestive in the absence of left ventricular hypertrophy or digitalis. Primary $\mathrm{T}$ wave abnormalities however may, in addition to ischaemia, be due to pericarditis, cardiomyopathy, mitral regurgitation, hypokalaemia, drugs such as digitalis or quinidine, or hypertensive crises (Surawicz, 1972). Other changes which may be ischaemic include atrial fibrillation in the absence of rheumatic heart disease (Davies and Pomerance, 1972) and complete AV block particularly in the form of bilateral bundle-branch block. These, however, are rare. Left bundle-branch block has been included in the criteria used here as probable evidence of ischaemic heart disease, yet Haft, Herman, and Gorlin (197I) and Lewis et al. (1970) in studies of this abnormality ascribe only some 50 per cent of cases to this cause.

It is of interest that the presence of left anterior hemiblock (Rosenbaum, 1970) was far commoner than either left or right bundle-branch block in this series of elderly patients, and after ST-T changes and left ventricular hypertrophy pattern it was the most common abnormality. The significance of this is not yet fully apparent. It is a common sequel to myocardial infarction but on the other hand may be present in other patients, presumably as a result of degenerative disease of the conducting tissue.

It is clear both that the specificity of the factors which can be taken as evidence of ischaemic heart disease is low and that the point in the evolution of this common condition at which the disease can be diagnosed as present is vague. Accepting these limitations, the best that can be done is to record the prevalence of various possible manifestations using standard criteria so that comparison may be made with other surveys. The points that emerge from the present survey are the striking increase in the prevalence of all stigmata of ischaemic heart disease with age. Though not unexpected, this represents a remarkable incidence of the disease when it is remembered that the cohorts studied are the survivors of high annual mortality rates from ischaemic heart disease. In this older age group there is little sex difference in prevalence figures, and the wellestablished relation between blood pressure and ischaemic heart disease brought out in prospective studies of mortality in younger subjects (Morris et al., 1966) is not evident.

Although the true prevalence of the disease in different age and sex groups probably runs parallel with the prevalence of the presumed manifestations, it would be rash to attempt to deduce actual prevalence rates from this or other cardiovascular surveys. The most unequivocal evidence is probably the existence of electrocardiographic abnormalities with angina, and in the present series this occurred in 7 per cent of cases. At the other extreme some 30 per cent have at least one manifestation which is suggestive of the disease. Some cases of serious coronary occlusive disease may be undetected by all of the current methods, and in a population sample such as this which is being studied longitudinally, the incidence of fresh changes may be evaluated much more precisely than the retrospective data.

This work was supported by a grant from the Secretary of State for Scotland, via the Advisory Committee on Medical Research.

\section{References}

Acheson, R. M. (196I). Aetiology of coronary heart disease in old men. British fournal of Preventive and Social Medicine, 15, 49.

Blackburn, H., Keys, A., Simonson, E., Rautaharju, P., and Punsar, S. (1960). The electrocardiogram in population studies. A classification system. Circulation, 21, 1160.

Davies, M. J., and Pomerance, A. (1972). Pathology of atrial fibrillation in man. British Heart fournal, 34, 520.

Dawber, T. R., Kannel, W. B., Revotskie, N., and Kazan, A. (1962). The epidemiology of coronary heart disease - the Framingham enquiry. Proceedings of the Royal Society of Medicine, 55, 265.

Edwards, D. A. W., Hammond, W. H., Healy, M. J. R., Tanner, J. M., and Whitehouse, R. H. (I955). Design and accuracy of calipers for measuring subcutaneous tissue thickness. British fournal of Nutrition, 9, 133. 
Eisenberg, H., Feltner, W. R., Payne, G. H., and Haddad, C. A. (196I). The epidemiology of coronary heart disease in Middlesex County, Connecticut. (I) A preliminary report on methodology and the incidence of primary myocardial infarction. Fournal of Chronic Diseases, 14, 221.

Friesinger, G. C., and Smith, R. F. (1972). Correlation of electrocardiographic studies and arteriographic findings with angina pectoris. Circulation, 46, 1173.

Grant, R. P. (1956). Left axis deviation; an electrocardiographic-pathologic correlation study. Circulation, 14, 233.

Haft, J. I., Herman, M. V., and Gorlin, R. (197I). Left bundle branch block: etiologic hemodynamic and ventriculographic considerations. Circulation, 43, 279.

Horan, L. G., Flowers, N. C., and Johnson, J. C. (I97I). Significance of the diagnostic $Q$ wave of myocardial infarction. Circulation, 43, 428.

Kennedy, R. D., and Caird, F. I. (1972). The application of the Minnesota Code to population studies of the electrocardiogram in the elderly. Gerontologia Clinica, 14, 5.

Lewis, C. M., Dagenais, G. R., Friesinger, G. C., and Ross, R. S. (1970). Coronary arteriographic appearances in patients with left bundle-branch block. Circulation, 4I, 299.

Lindberg, H. A., Berkson, D. M., Stamler, J., and Poindexter, A. (1960). Totally asymptomatic myocardial infarction: an estimate of its incidence in the living population. Archives of Internal Medicine, 106, 628.

Lovell, R. R. H., and Prineas, R. J. (197I). Mechanisms of sudden death under implications for prevention and management. Progress in Cardiovascular Diseases, 13, 482.

Medical Research Council Committee on the Aetiology of Chronic Bronchitis (1965). Definition and classification of chronic bronchitis. Lancet, $\mathbf{1}, 775$.

Milne, J. S., Hope, K., and Williamson, J. (r971a). Variability in replies to a questionnaire on physical health. Fournal of Chronic Diseases, 22, 805.

Milne, J. S., Maule, M. M., and Williamson, J. (1971b). Method of sampling in a study of older people with a comparison of respondents and non-respondents. British fournal of Preventive and Social Medicine, 25, 37.

Morris, J. N., Kagan, A., Pattison, D. C., Gardner, M. J., and Raffle, P. A. B. (1966). Incidence and prediction of ischaemic heart-disease in London busmen. Lancet, 2, 553.

Pathy, M. S. (1967). Clinical presentation of myocardial infarction in the elderly. British Heart fournal, 29, 190.

Painter, R. C., Ralston, L. S., Fawcett, R. M., Zukel, W. J., and Lewis, R. H. (1960). Short-term study of coronary heart disease in a North Dakota community. Fournal of the American Medical Association, 172, 1261 .

Paul, O., Lepper, M. H., Phelan, W. H., Dupertuis, G. W., MacMillan, A., McKean, H., and Park, H. (I963). A longitudinal study of coronary heart disease. Circulation, 28, 20.

Reid, D. D., Cornfield, J., Markush, R. E., Seigel, D., Pedersen, E., and Haenszel, W. (1966a). Studies of disease among migrants and native populations in Great Britain, Norway, and the United States. 3. Prevalence of cardiorespiratory symptoms among migrants and native-born in the United States. National Cancer Institute Monographs, 19, 32 .

Reid, D. D., Holland, W. W., Humerfelt, S., and Rose, G. (I966b). A cardiovascular survey of British postal workers. Lancet, $\mathrm{r}, 6 \mathrm{r} 4$.

Rose, G. A. (1962). The diagnosis of ischaemic heart pain and intermittent claudication in field surveys. Bulletin of the World Health Organization, 27, 645.

Rose, G. (1967). Surveys of the prevalence of ischaemic heart disease in certain European countries. In Studies of the Prevalence of Ischaemic Heart Disease, Report on a technical meeting. W.H.O. Regional Office for Europe. p. 9. Copenhagen.

Rose, G. A. (1968). Variability of angina. British fournal of Preventive and Social Medicine, 22, 12.

Rose, G. A. (197I). Predicting coronary heart disease from minor symptoms and electrocardiographic findings. British fournal of Preventive and Social Medicine, 25, 94.

Rose, G. A. (1972). Epidemiology of ischaemic heart disease. British fournal of Hospital Medicine, 7, 285.

Rose, G. A., and Blackburn, H. (1968). Cardiovascular Survey Methods. World Health Organization, Geneva.

Rosenbaum, M. B. (1970). The hemiblocks; diagnostic criteria and clinical significance. Modern Concepts of Cardiovascular Disease, 39, I4I.

Säwe, U. (I97I). Pain in acute myocardial infarction. A study of 137 patients in a coronary care unit. Acta Medica Scandinavica, 190, 79.

Stamler, J., Lindberg, H. A., Berkson, D. M., Shaffer, A., Miller, W., and Poindexter, A. (1960). Prevalence and incidence of coronary heart disease in strata of the labor force of a Chicago industrial corporation. Fournal of Chronic Diseases, Ir, 405.

Surawicz, B. (1972). The pathogenesis and clinical significance of primary $\mathrm{T}$ wave abnormalities. In Advances in Electrocardiography, pp. 377-421. Ed. by R. C. Schlant and J. W. Hurst. Grune and Stratton, New York; Academic Press, London.

Zeiner-Henriksen, T. (1972). The repeatability at interview of symptoms of angina and possible infarction. Fournal of Chronic Diseases, 25, 407.

Requests for reprints to Dr. A. H. Kitchin, Department of Medicine, Western General Hospital, Edinburgh $\mathrm{EH}_{4} 2 \mathrm{XU}$. 